\title{
Sacred sites as hotspots for biodiversity: the Three Sisters Cave complex in coastal Kenya
}

\author{
Kristian Metcalfe, Richard Ffrench-Constant and Ian Gordon
}

\begin{abstract}
Sacred sites, particularly in forests, often form unofficial protected areas because their biodiversity is preserved and protected by the local people looking after the sites. Here, we survey the biodiversity of the Three Sisters Cave complex, a sacred site or kaya in a fragment of East African coastal forest in south-east Kenya. We show that, despite the tiny size of this non-gazetted forest reserve, it contains many of the threatened species of both flora (121 species) and fauna (46 species) representative of Kenya's coastal forest. Following the overexploitation and widespread destruction of coastal rainforests in Kenya, such sacred sites represent key biodiversity hotspots as well as forest islands in the now largely deforested coastal plain. Other non-gazetted forest sacred sites may represent undocumented sources of biodiversity that may contribute towards conservation of this threatened coastal habitat.
\end{abstract}

Keywords Cave, coastal forest, East Africa, fauna, flora, hotspot, Kenya, sacred site

This paper contains supplementary material that can be found online at http://journals.cambridge.org

\section{Introduction}

Cacred sites are defined as specific places recognized by $\checkmark$ indigenous and traditional people as having cultural, historical, spiritual and religious significance or as sites established by institutionalized religions and faiths as places for worship and remembrance (Jeanrenaud, 2001). They occur in different forms, including remnants of old forests, caves, burial grounds and sites of ancestral worship (Mgumia \& Oba, 2003). Sacred sites are important as a tool for in situ conservation of flora and fauna because of their widespread distribution and their roles as reservoirs for local biodiversity and threatened species (Mgumia \& Oba, 2003).

Kristian Metcalfe* (Corresponding author) and Richard FfrenchCOnstant Centre for Ecology and Conservation, School of Biosciences, University of Exeter, Cornwall Campus, Penryn, Cornwall, UK. E-mail kristian.metcalfe@hotmail.com

IAN GORDON International Centre for Insect Physiology and Ecology, Nairobi, Kenya.

${ }^{*}$ Current address: Durrell Institute of Conservation and Ecology, University of Kent, Canterbury, Kent, CT2 7NR, UK.

Received 13 December 2008. Revision requested 27 January 2009. Accepted 12 March 2009.
Approximately 3,170 $\mathrm{km}^{2}$ of East Africa's coastal forest remains, in Somalia, Kenya, Tanzania, Mozambique, Zimbabwe and Malawi (Burgess \& Clarke, 2000; Azeria et al., 2007), of which $660 \mathrm{~km}^{2}$ is in Kenya (20.82\%; Burgess et al., 1998). Kenya's coastal forests are biologically rich and harbour high concentrations of endemic species (Myers et al., 2000). However, a long history of anthropogenic disturbance has reduced the forest to small remnant patches. The protection status of these forest patches in Kenya varies considerably. The largest forest on the coast is Shimba Hills National Reserve $\left(>_{150} \mathrm{~km}^{2}\right)$, which is gazetted by both the Forest Department and Kenya Wildlife Service (Robertson \& Luke, 1993). The remaining forest patches, in order of decreasing protection status, are (1) gazetted forest reserves and community sanctuaries, (2) sacred groves or kaya, some of which are gazetted as national monuments, and (3) unprotected forests on private or county council-owned land (Anderson et al., 2007a). While sacred sites were not created for biodiversity conservation their complex social, spiritual and cultural associations have contributed to the protection of some ecosystems and, because they frequently have a higher concentration of floral diversity than managed ecosystems, they can be considered an important refuge for threatened species (Mgumia \& Oba, 2003).

Sacred sites on Kenya's coastal strip, often referred to as $k a y a$, tend to be residual patches of the once extensive diverse lowland forest of the Zanzibar-Inhambane Regional Mosaic (Burgess \& Clarke, 2000) and have high conservation value because of their botanical diversity (Robertson, 1986; Robertson \& Luke, 1993; Githitho, 1998). They owe their existence to the beliefs and culture of the nine coastal Mijikenda ethnic groups (Chonyi, Digo, Duruma, Giriama, Jibana, Kambe, Kauma, Rabai and Ribe; Githitho, 1998). Cutting of trees and destruction of vegetation in and around these sites were prohibited by local village elders in an attempt to preserve the historical and traditional values of these sites. However as a result of economic, social, and cultural changes in society there has been a decline in knowledge about, and respect for, traditional values. In addition, more formal education, and government policy to reduce dependence on witchcraft, has led to a decline in respect for elders (Githitho, 1998; Matiku, 2003). As a result of the loss of traditional values and leadership, combined with a rising demand for forest products and land for agriculture, mining, tourism and other activities, many sacred sites have been lost (Githitho, 1998). However, some sites still remain as forest patches of varying size and significance. 
Although sacred sites are known to be useful for conservation there has been no coordinated attempt to assess their contribution to biodiversity (Mgumia \& Oba, 2003) and little is known about the belief systems that have helped conserve such sites (Jeanrenaud, 2001). Given the lack of inventories of sacred sites in coastal Kenya and the importance of this area as a biodiversity hotspot and priority region for international conservation investment (Myers et al., 2000; Brooks et al., 2001), a floral and faunal survey was undertaken at a previously undocumented sacred site, the Three Sisters Caves. We aimed to provide the basis for future studies by mapping the cave complex, identifying and documenting the flora and fauna at the site, and describing any threats.

\section{Study area}

The Three Sisters Caves are in Kwale district, one of seven administrative districts in coastal Kenya, between Mombasa and the border with north-east Tanzania (Anderson et al., 2007b; Fig. 1). The c. $8,322 \mathrm{~km}^{2}$ district contains a heterogeneous mix of grassland, woodland, swamp, shrub land, forestry plantation, mangrove and agricultural land (both commercial and subsistence crops). Mean annual temperature is $26^{\circ} \mathrm{C}$ and rainfall is bimodal (March-July and October-December), with the $36-\mathrm{km}$ wide coastal strip receiving a total annual rainfall of $900-1,500 \mathrm{~mm}$ (Burgess \& Clarke, 2000).

The Caves are in a remnant of the coastal forest belt, which was once a continuous mosaic of forest, thicket, woodland, bush land and grassland. The Eastern Arc Mountains and Coastal Forest Hotspot run along the Tanzanian and Kenyan coasts from the border with Somalia in the north to that with Mozambique in the south. This area is often referred to as the Northern Zanzibar-Inhambane Floristic Region (Burgess et al., 2007) and was recently reclassified as the Swahilian Regional Centre of Endemism (Clarke, 1998). The biodiversity of this hotspot is of global significance (Myers et al., 2000; Brooks et al., 2001), with at least 1,500 plant species, 16 endemic mammals, 22 endemic birds, 50 endemic reptiles and 33 endemic amphibians (Burgess \& Clarke, 2000; Myers et al., 2000). Because of the small area of the hotspot the densities of these endemics are among the highest in the world (CEPF, 2003). The Eastern Arc Mountains and Coastal Forest Hotspot is one of 25 global biodiversity hotspots (Myers et al., 2000; Brooks et al., 2002) and ranks first among the 25 hotspots in the density of endemic plant and vertebrate species. In addition, this ecoregion is one of 11 hyper-hot priority regions for international conservation investment (Brooks et al., 2002).

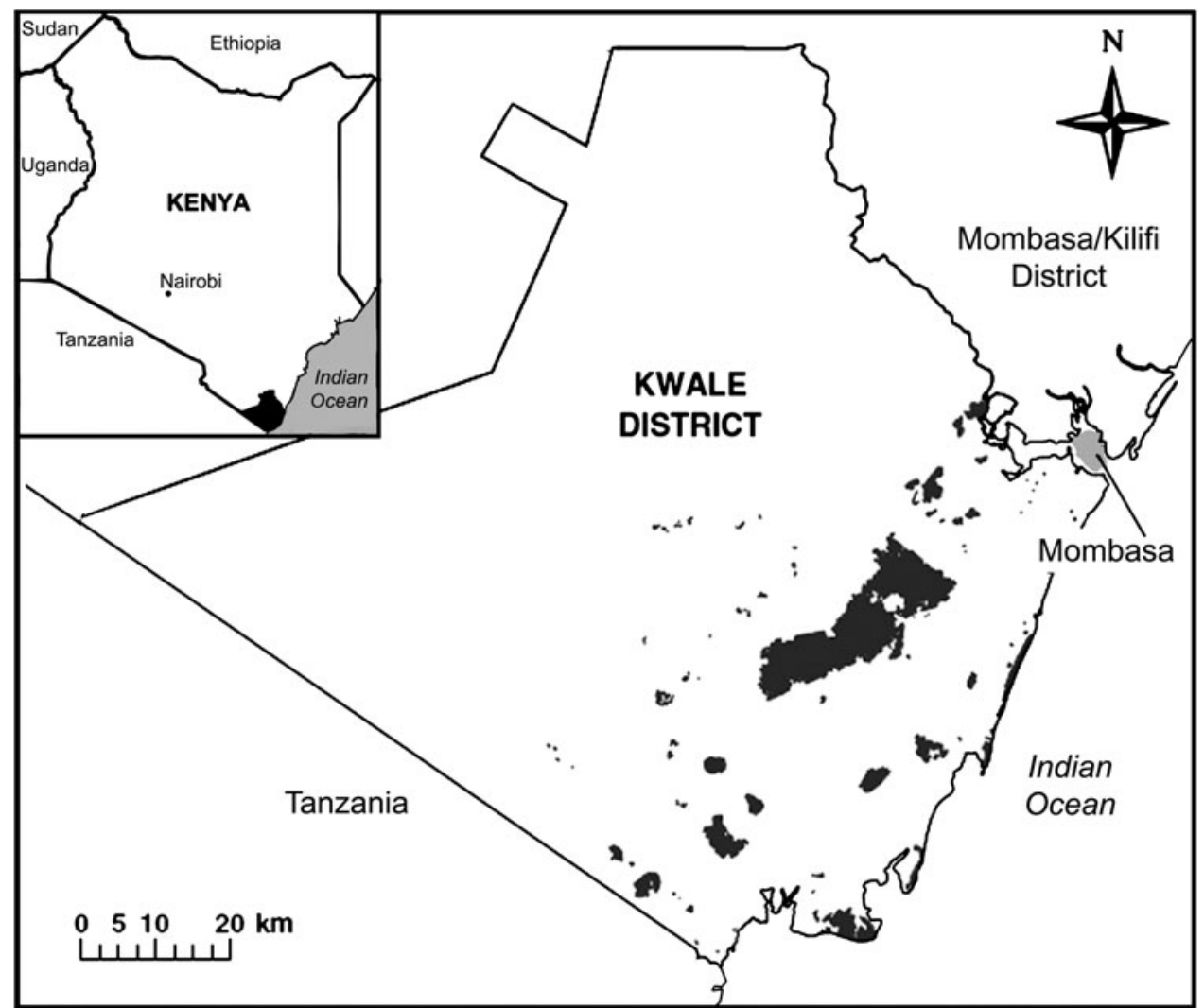

FIG. 1 Kwale district, showing the coastal forest fragments (shaded black). The inset indicates the position of the main map in Kenya. Based on Anderson et al. (2007b). 
The Three Sisters Caves are formed from limestone and are in the middle of a small remnant of ancient coastal forest in Fikirini, c. $70 \mathrm{~km}$ south of Mombasa and $15 \mathrm{~km}$ north of Shimoni. Geologically, the coastal forest strip has been subjected to considerable tectonic activity and to sedimentation and erosion associated with movements of the shoreline (Burgess \& Clarke, 2000), resulting in the formation of several limestone cave systems. The forest zone lies on ancient coral reef exposed by falling sea levels, the results of which are limestone rock covered by relatively shallow soils. The thin soils mean that the tree species of the coastal forest belt are highly specialized and consequently support and sustain a number of rare and endemic species of particular conservation and scientific interest.

Although the site has not been gazetted as a monument its three caves (Pangani, Kisimani and Midenyenye) were once used for traditional ceremonies and worship and were an important refuge during tribal conflicts and the slave trade. It is this past cultural and historical association that have led to their protection by the local community (A.B. Toya, pers. comm.). We took appropriate action to ensure that the local community was aware of the research to be undertaken, and permission to access the site was granted by elders from Fikirini village on the proviso that a villager accompany the researchers.

\section{Methods}

This research was carried out during March-June 2008. The individual cave complexes were mapped using a tape measure and compass. All measurements were from the base of the cave wall. Measurements started at the entrance, with the compass point set on north; the angle of the cave wall relative to north was recorded and the distance to the next angle (change in direction of the cave wall) measured. This method was repeated at every change in angle until the surveyor returned to the opposite side of the entrance. The approximate location of holes in the roof, sources of water and areas of rock fall and vegetation were documented.

Vegetation surveys of the coastal forest remnant in which the Three Sisters Cave complex is situated were undertaken by walking 15 transects, $5 \mathrm{~m}$ apart, through the forest, recording all tree and shrub species. Plants were identified using standard references for the area (Noad \& Birnie, 1990; Beentje, 1994) and were undertaken with assistance from the Coastal Forest Conservation Unit. The name of each species was recorded in Digo and Kiswahili, and further information was provided on the medicinal and material values of each species by the elders and villagers, with inclusions from Beentje (1994).

We used a number of methods to make a comprehensive inventory of fauna in the cave complex and the forest remnant. Amphibian surveys were conducted visually for 15 minutes each week for 8 weeks ( 2 hours per cave) in the caves Pangani and Kisimani, which contain water. Cave invertebrates were identified using visual searching techniques (Hunt \& Millar, 2001); those that were difficult to identify in the field were collected and preserved in $70 \%$ ethanol for later identification (Sharratt et al., 2000). To establish the location of bat species and their roosts the individual caves were subdivided into their separate chambers, of which there are three for Pangani and Kisimani and seven for Midenyenye. Because of the small size of several of the surveyed chambers bats were captured using a net $(100 \times 50 \mathrm{~cm})$ attached to an extendable pole $(1-5 \mathrm{~m})$. This allowed bats to be captured from a range of heights and locations. To cause minimal disturbance to the bats 30 minutes was allocated to capture a minimum of 15 bats in each chamber, every other day, for 1 week ( 4 days: 26 hours of survey). Captured bats were released after being photographed (head, ear, body, tail and feet) and identified (Kingdon, 1997). Mammals and reptiles recorded in the caves and forest remnant were encountered in the process of other surveys. Primate surveys were conducted in conjunction with the vegetation transects.

\section{Results}

A total of 121 plant species in 43 families and 97 genera were recorded (Appendix), representing 1.9\% of Kenya's 6,500 floral species (Luke, 2005) and $8.1 \%$ of the 1,500 species in the Eastern Arc Mountains and Coastal Forest Hotspot (Burgess \& Clarke, 2000; Myers et al., 2000). The families with the most species were Leguminosae (12 species), Rubiaceae (11), Moraceae (nine) and Euphorbiaceae (nine). The genera with the most species were Ficus (four species), Psychotria (three), Gymnosporia (three) and Rinorea (three). Table 1 presents an overview of the phytogeographical affinities of the flora. Three species occurring in this area are Kenya coastal endemics, restricted to Kenya coastal districts within the area of the Zanzibar-Inhambane Regional Mosaic, and 21 species are Zanzibar-Inhambane endemics (Luke, 2005). Nine species have some form of rarity status as defined

TABle 1 Phytogeographical affinities of the flora recorded at the Three Sisters Caves sacred site and coastal forest remnant, using the categories of Robertson \& Luke (1993) and Luke (2005).

\begin{tabular}{lc}
\hline & No. of species \\
\hline Kenyan coastal endemics & 3 \\
Kenyan Somalia/Masai endemics & 0 \\
Zanzibar/Inhambane endemics & 21 \\
Somalia/Masai endemics & 0 \\
Zanzibar/Inhambane + one other region & 17 \\
Pan African & 38 \\
Pan Tropical & 17 \\
Unassigned & 25 \\
Total & 21 \\
\hline
\end{tabular}


by the Coastal Forest Survey (Table 2; Robertson \& Luke, 1993). One is considered a rare species worldwide (Barleria whytei), five are considered rare in Kenya but occur outside the country (Amorphophallus maximus, Macphersonia gracilis var. hildebrandtii, Pristimera andongensis, Ricinodendron heudelotii and Rinorea ferruginea) and three are rare Kenya coastal species but occur elsewhere in Kenya or outside the country (Erythrina abyssinica, Keetia gueinzii and Vepris simplicifolia). Three species are categorized as Vulnerable on the IUCN Red List (IUCN, 2009) because of their restricted range and habitat (Angylocalyx braunii, Coffea pseudozanguebariae and Uvariodendron kirkii) and one species as Lower Risk/Near Threatened (Milicia excelsa). Three nonnative species were recorded, two of which are exotic species (Moringa oleifera and Artocarpus heterophyllus) and one of which is an alien invasive (Azadirachta indica; Robertson \& Luke, 1993). Of the species recorded, $42 \%$ (51 species) are documented to be of medicinal or material value to the local community.

The faunal survey identified 46 species in 8 Classes and 16 Orders (Appendix). The greatest number of species were in the Classes Insecta (18 species), Mammalia (12), Amphibia (four) and Reptilia (four). Of the 46 species one is categorized as Data Deficient (Heliosciurus undulatus; IUCN, 2009) and 12 are categorized Least Concern, indicating that the species have been assessed and found to be under no threat of extinction at present, of which Colobus angolensis palliatus is described as a flagship species for Kenya's remaining fragmented coastal forests (Anderson et al., 2007a). Two species are categorized as Near Threatened (Hipposideros commersoni and Miniopterus schreibersii) and one as Vulnerable (Taphozous hildegardeae). Hildegarde's tomb bat $T$. hildegardeae has only been recorded at nine locations, in south-east Kenya, northern Tanzania and

TABLE 2 Percentage of rare species of plants recorded at the Three Sisters Caves and forest remnant and in the seven kaya forests included on Robertson \& Luke's (1993) list of the 20 forests with the highest conservation value in coastal Kenya.

\begin{tabular}{lll}
\hline kaya & No. of species & \% rare species* \\
\hline Jibana/Pangan & 354 & 19.8 \\
Kinondo & 112 & 14.3 \\
Dzombo & 361 & 10.0 \\
Mrima & 271 & 9.2 \\
Muhaka & 278 & 9.0 \\
Three Sisters Caves & $\mathbf{1 2 1}$ & 7.4 \\
Rabai & 425 & 4.7 \\
Kivara & 170 & 3.5 \\
\hline
\end{tabular}

${ }^{\star}$ Incorporates the following Coastal Forest Survey (CFS) definitions: Rare species, those that are rare globally and found in $<5$ localities in the CFS area. Rare Kenya species, those found in $<5$ localities in Kenya but may occur elsewhere outside Kenya. Rare Kenya coastal species, those found in $<5$ localities within the CFS area but occur elsewhere in Kenya and outside.
Zanzibar, since it was first documented in 1909 (Colket \& Wilson, 1998), and the Three Sisters Caves is a previously unknown location. The distribution of the four bat species and the location of their respective roosts are indicated in Fig. 2.

\section{Discussion}

The results of the floral and faunal surveys indicate that the cultural and historical values held by the local community have resulted in the Three Sisters Caves and coastal forest remnant becoming a reservoir for local biodiversity. The site is particularly diverse botanically, with a number of rare species. This is consistent with studies undertaken by the Coastal Forest Survey at gazetted kaya forests throughout coastal Kenya (Robertson \& Luke, 1993; Table 2). The number of rare species recorded at these sites may be a reflection of ecological variation as sacred sites cover a broad range of habitat and microclimatic conditions (Githitho, 1998). The majority of the plant species recorded in the Three Sisters Caves coastal forest remnant are confined to the Eastern Arc Mountains and Coastal Forest Hotspot, with a number of species of conservation concern as defined by the Coastal Forest Survey (nine species) and as categorized on the IUCN Red List (four species) because of their restricted range, habitat loss and the increasing threat of human disturbance. Unfortunately, like most East African forest-dependent species, habitat destruction and human disturbance are major threats to their survival (CEPF, 2003).

Sacred sites comprise c. $60 \mathrm{~km}^{2}(10 \%)$ of Kenya's remaining coastal forest (Githitho, 1998). Along the south coast sacred sites are facing increasing pressure from clearance for hotel developments and settlement schemes (Githitho, 1998). Despite local protection the fauna and flora of the Three Sisters Caves and coastal forest remnant are threatened because of the needs of the impoverished local people. Anderson et al. (2007a) indicated that unprotected forests in the Kwale district are heavily exploited because of habitat destruction linked to human population growth, agricultural expansion and tourist development (CEPF, 2003; Azeria et al., 2007). Illegal logging of trees for charcoal, fuelwood, building poles, furniture, construction timber and wood carving (in particular for the tourist market), and coral block mining, are the most prominent activities occurring in the vicinity of the Three Sisters Caves (K. Metcalfe, pers. obs.).

Our study clearly highlights the significant contribution that sacred sites may play in the conservation of Kenya's biodiversity and particularly for its fragmented coastal forests. There have been a number of biodiversity investigations and conservation efforts in the Eastern Arc Mountains and Coastal Forest Hotspot in the past decade (CEPF, 2003) but there are still significant gaps in knowledge, 


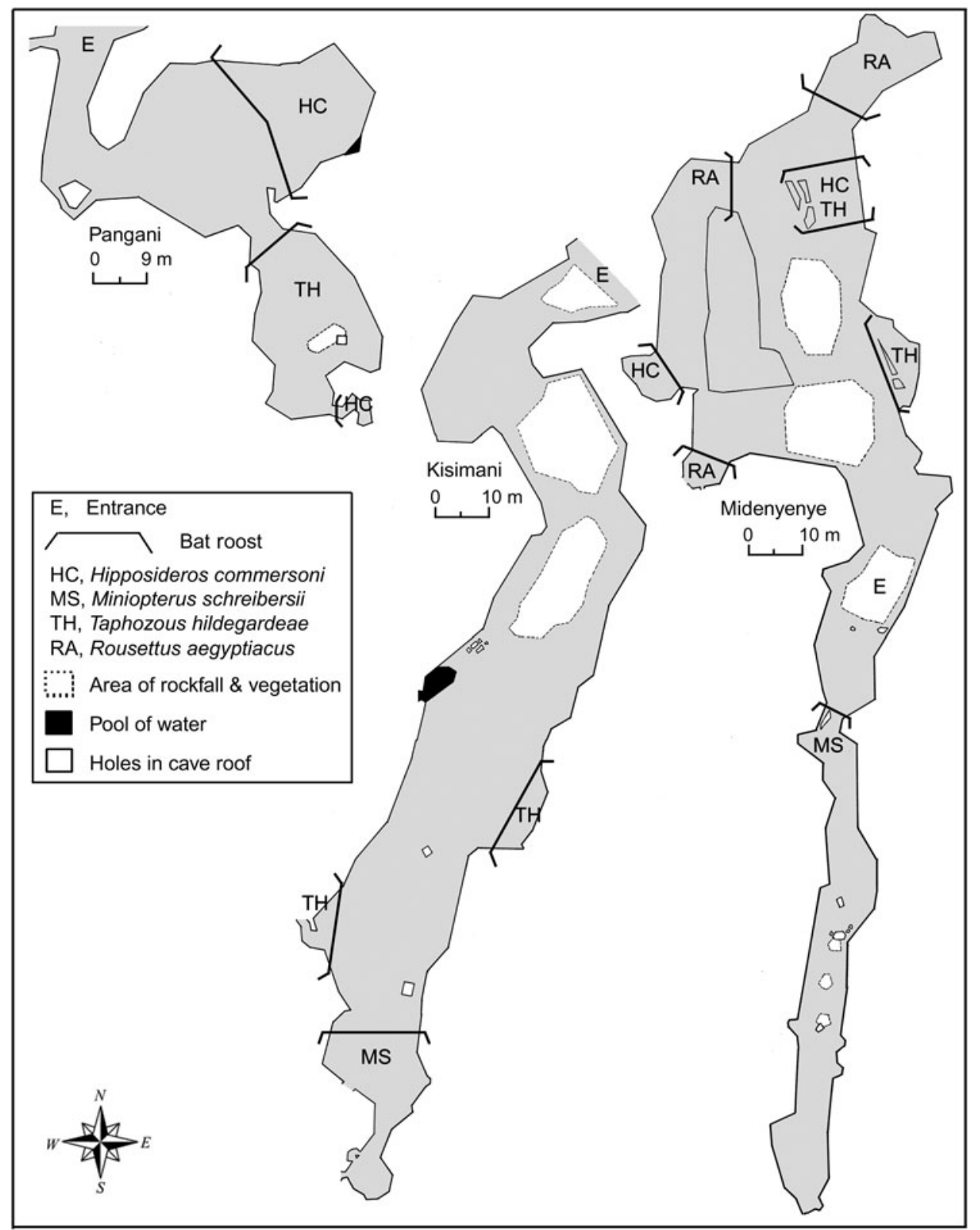

FIG. 2 The Three Sisters Caves at Fikirini in Kwale district, Kenya (Fig. 1), showing the distribution and location of the roosts of Hipposideros commersoni, Miniopterus schreibersii, Taphozous hildegardeae and Rousettus aegyptiacus. The positions of the caves in the figure are for convenience and do not reflect their relative positions.

particularly with respect to the number of sacred sites that remain unprotected and undocumented. Joint attempts need to be made by conservationists and local communities to address the problems and destruction affecting the sacred sites on Kenya's coastal strip.

\section{Acknowledgements}

We thank the elders of Fikirini village for giving us permission to undertake our work, in particular Seif Mzee Mwatao, Ali Bakari Toya and Bakar Mwabweko Kuchi, and Peter and Sandra Ruysenaars of Pemba Channel Lodge,
Shimoni for accommodation. We are especially grateful to the following for their invaluable help: Dr Robert Drewes (Curator of Herpetology, California Academy of Sciences), Dr David Hosken (University of Exeter), Dr Paul Bates (The Harrison Institute) and Dr Anthony Start (Department of Environment and Conservation, Australia) for assistance with identification of bats; Dr George Beccaloni (Curator of Orthoptera, Natural History Museum, London), Darren John Mann (Oxford University Museum of Natural History) and Dr Lorenzo Prendini (American Museum of Natural History, New York) for assistance with invertebrate identification; Saidi Chidzinga of the Coastal 
Forest Conservation Unit, Ukunda, for assistance with the vegetation surveys and $\mathrm{Dr}$ Quentin Luke, National $\mathrm{Mu}-$ seums of Kenya, for reviewing the results.

\section{References}

Anderson, J., Cowlishaw, G. \& Rowcliffe, J.M. (2007a) The Angola black and white colobus (Colobus angolensis palliatus) in Kenya: historical range contraction and current conservation status. American Journal of Primatology, 69, 664-680.

Anderson, J., Cowlishaw, G. \& Rowcliffe, J.M. (2007b) Effects of forest fragmentation on the abundance of Colobus angolensis palliatus in Kenya's coastal forests. International Journal of Primatology, 28, 637-655.

Azeria, E.T., Sanmartin, I., Stephan, A.S., Carlson, A. \& Burgess, N.D. (2007) Biogeographic patterns of the East African coastal forest vertebrate fauna. Biodiversity and Conservation, 16, 883-912.

Beentje, H. (1994) Kenya Trees, Shrubs \& Lianas. National Museum of Kenya, Nairobi, Kenya.

Brooks, T.M., Balmford, A., Burgess, N.D., Fjelds Å, J., Hansen, L.A., Moore, J. et al. (2001) Towards a blueprint for conservation in Africa. Bioscience, 51, 613-624.

Brooks, T.M., Mittermeier, R.A., Mittermeier, C.G., da Fonseca, G.A.B., Rylands, A.B., Konstant, W.R. et al. (2002) Habitat loss and extinction in the hotspots of biodiversity. Conservation Biology, 16, 909-923.

Burgess, N.D., Butynski, T.M., Cordeiro, N.J., Doggart, N.H., FJelds⿱ J., Howell, K.M. et al. (2007) The biological importance of the Eastern Arc Mountains of Tanzania and Kenya. Biological Conservation, 134, 209-231.

Burgess, N.D. \& Clarke, G.P. (eds) (2000) The Coastal Forests of Eastern Africa. IUCN, Gland, Switzerland, and Cambridge, UK.

Burgess, N.D., Clarke, G.P. \& Rodgers, W.A. (1998) Coastal forests of eastern Africa: status, endemism patterns and their potential causes. Biological Journal of the Linnean Society, 64, $337-367$.

CEPF (Critical Ecosystem Partnership Fund) (2003) Ecosystem Profile: Eastern Arc Mountains and Coastal Forests of Tanzania and Kenya Biodiversity Hotspot. Critical Ecosystem Partnership Fund, Washington, DC, USA. Http://www.cepf.net/xp/cepf/where_we_ work/eastern_arc_mountains/full_strategy.xml [accessed 3 February 2009].

Clarke, G.P. (1998) A new regional centre of endemism in Africa. In Aspects of the Ecology, Taxonomy and Chorology of the Floras of Africa and Madagascar (eds D.F. Cutler, C.R. Huxley \& J.M. Lock), pp. 53-65. Royal Botanical Gardens, Kew, UK.

Colket, E. \& Wilson, D.E. (1998) Taphozous hildegardeae: mammalian species. American Society of Mammalogists, 597, 1-3.

Giтнiтно, A. (1998) Institutional Challenges in Conservation: The Case of the Sacred Kaya Forests of the Kenyan Coast. The World Bank/WBL's CBNRM Initiative, Washington, DC, USA. Http:// srdis.ciesin.columbia.edu/cases/kenya-oo6.html [accessed 3 February 2009].

Hunt, M. \& Millar, I. (2001) Cave Invertebrate Collecting Guide: Technical Series 26. Department of Conservation, Wellington, New Zealand.
IUCN (2009) IUCN Red List of Threatened Species v. 2009.1. IUCN, Gland, Switzerland. Http://www.iucnredlist.org [accessed 18 September 2009].

Jeanrenaud, S. (2001) An International Initiative for the Protection of Sacred Natural Sites and other Places of Indigenous and Traditional Peoples with Importance for Biodiversity Conservation. WWF International, Gland, Switzerland.

Kingdon, J. (1997) The Kingdon Field Guide to African Mammals. Harcourt Brace and Company, San Diego, USA.

Luke, W.R.Q. (2005) Annotated check-list of the plants of the Shimba Hills, Kwale District, Kenya. Journal of East African Natural History, 94, 5-120.

Mатікu, P. (2003) The Coastal Forests of Kenya: Forests Data, Threats, Socio-Economic Issues, Values, Stakeholders, Challenges, Strategies, Investment and Enabling Environment. A National Synthesis Report for the Development of the WWF-EARPO Eastern Africa Coastal Forests Ecoregion Programme. Nature Kenya, Nairobi, Kenya. Http://cf.tfcg.org/pubs/National-SynthesisKen.pdf [accessed 3 February 2009].

Mgumia, F.H. \& Ова, G. (2003) Potential role of sacred groves in biodiversity conservation in Tanzania. Environmental Conservation, 30, 259-265.

Myers, N., Mittermeier, R.A., Mittermeier, C.G., Da Fonseca, G.A.B. \& Kent, J. (2000) Biodiversity hotspots for conservation priorities. Nature, 403, 853-858.

Noad, T. \& Birnie, A. (1990) A Fully Illustrated Field Guide: Trees of Kenya. General Printers Ltd, Nairobi, Kenya.

Robertson, S.A. (1986) Preliminary Floristic Survey of the Kaya Forests of Coastal Kenya. Unpublished Report. National Museums of Kenya, Nairobi, Kenya.

Robertson, S.A. \& Luke, W.R.Q. (1993) Kenya Coastal Forests: Coast Forest Status, Conservation and Management. WWF, Nairobi, Kenya.

Sharratt, N.J., Picker, M.D. \& Samways, M.J. (2000) The invertebrate fauna of the sandstone caves of the Cape Peninsula (South Africa): patterns of endemism and conservation priorities. Biodiversity and Conservation, 9, 107-143.

\section{Appendix}

The appendix for this article is available online at http:// journals.cambridge.org

\section{Biographical sketches}

Kristian Metcalfe has undertaken research on a range of conservation projects in Europe and Africa. He is particularly interested in the marine environment, with particular focus on biodiversity assessments, threatened species and habitat management. Richard FFrench-Constant is interested in butterfly colour patterns, insecticide resistance and insect parasitism. He was born in Nairobi and maintains a keen interest in conservation issues in Kenya. IAN Gordon is Chairman of Nature Kenya, the national BirdLife partner in Kenya, and is an entomologist with interests in evolutionary and conservation biology. 